DIW BERLIN

Discussion

Papers

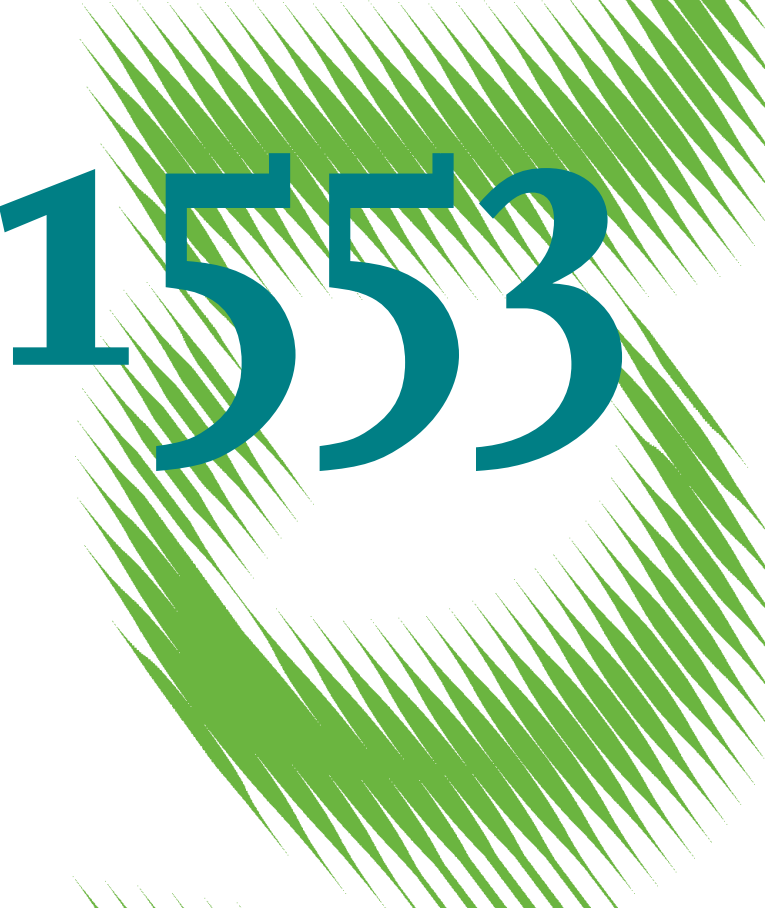

North American Natural Gas Model Impact of Cross-Border Trade with Mexico 
Opinions expressed in this paper are those of the author(s) and do not necessarily reflect views of the institute.

IMPRESSUM

(C) DIW Berlin, 2016

DIW Berlin

German Institute for Economic Research

Mohrenstr. 58

10117 Berlin

Tel. +49 (30) $89789-0$

Fax +49 (30) $89789-200$

http://www.diw.de

ISSN electronic edition 1619-4535

Papers can be downloaded free of charge from the DIW Berlin website:

http://www.diw.de/discussionpapers

Discussion Papers of DIW Berlin are indexed in RePEc and SSRN:

http://ideas.repec.org/s/diw/diwwpp.html

http://www.ssrn.com/link/DIW-Berlin-German-Inst-Econ-Res.html 


\section{North American Natural Gas Model Impact of cross-border trade with Mexico}

Felipe Feijoo $^{\mathrm{a}}$, Daniel Huppmann ${ }^{\mathrm{b}, \mathrm{d}}$ Larissa Sakiyama $^{\mathrm{a}}$ Sauleh Siddiqui ${ }^{\mathrm{a}, \mathrm{c}, \mathrm{d}}$

February 10, 2016

Natural gas as a source of energy has attracted a lot of interest as its emissions rate and price are lower than other fossil fuel energy sources. In the U.S., natural gas-fired power generation has been rising, as coal has declined as a share of the fuel mix. Likewise, Mexico recently launched its energy reform with focus on greatly expanding use of natural gas over other fossil fuels, primarily in the energy sector, by opening the market to private investors. These recent economic and policy changes, along with increasing gas production in the U.S. (shale gas boom) are likely to drive the natural gas market in North America in a new direction. For instance, the Annual Energy Outlook 2015 describes the U.S. for the first time as a net exporter of natural gas (via pipelines and LNG) by 2017.

In order to study the current North American gas market with its new regulations like the Mexican energy reform, this paper presents the North American Natural Gas Market Model (NANGAM). We propose a longterm partial-equilibrium model of the United States, Mexican, and Canadian gas markets. NANGAM considers more granular details regarding market regions and pipelines in Mexico than other existing models, allows for endogenous infrastructure expansion, and is built in five year timesteps up to 2040, considering three seasons (low, high, and peak demand) for each time-step. NANGAM is calibrated using up-to-date data, which reflects current gas market trends, such as the increasing U.S. shale gas production. Using NANGAM, we assess the implications of the Mexican energy reform using a set of ad-hoc future scenarios. Results from the model show that, in the case of disappointing development of natural gas production in Mexico, the census region US7 (Texas and adjacent states) is the most affected, reaching an increase of natural gas production of up to $12 \%$ by 2040 compared to baseline projections.

Keywords: North American natural gas scenarios, Mexican energy reform, dynamic market equilibrium model, mixed complementarity problem, infrastructure investment, capacity investment

JEL Codes: Q41, L71, Q37, C61

a Department of Civil Engineering, Johns Hopkins University, Baltimore, MD 21218, USA

b International Institute for Applied Systems Analysis (IIASA), 2361 Laxenburg, Austria

c Department of Applied Mathematics and Statistics \& Johns Hopkins Systems Institute, Johns Hopkins University, Baltimore, MD 21218, USA

d German Institute for Economic Research (DIW Berlin), 10117 Berlin, Germany

E-mail: ffeijoo@jhu.edu,huppmann@iiasa.ac.at, larissa.sakiyama@ufv.br, siddiqui@jhu.edu 


\section{Introduction}

The US shale boom and new power plant regulations recently announced by the Environmental Protection Agency (EPA), aiming to curb greenhouse gas emission and mitigate global warming, have stimulated substantial academic debate and numerical simulation exercises to understand the future role of natural gas in North America (e.g., Huntington, [2007, 2015). Furthermore, the US is expected to become a significant net exporter of natural gas over the next years, as China and Mexico are shifting from its reliance on coal to cleaner alternatives. Alas, to date, there is very little academic focus on the role of Mexico.

Natural gas demand grew by $64 \%$ in Mexico between 2004 and 2013, primarily led by the increasing consumption from the electricity sector. Due to a lack of investment incentives, production did not increase at the same pace as demand, and proven gas reserves in Mexico decreased from 2.0 trillion cubic meters in 1993, to $0.4 \mathrm{tcm}$ in 2003 and $0.3 \mathrm{tcm}$ in 2013 (BP, 2015$)$. Production growth of natural gas in the South-Southeast Mexican region is projected to be $0.4 \%$ per year through 2019 (Congressional Research Service, 2015). Mexico's state-owned petroleum company, PEMEX, consumes increasing portions of this gas production for exploration, production, and refining activities ${ }^{m}$. Combining these circumstances with limited future LNG importing capacity, pipeline imports from the U.S. are crucial to meet growing national demand (EIA, [2014).

Approximately $69 \%$ of Mexico's gas imports came from the U.S. in 2014, making Mexico have one the highest levels of dependency from a single supplier (Biresselioglu et al., 2015). Pipeline flows from the U.S. to Mexico averaged 2 billion cubic feet per day $(\mathrm{Bcf} / \mathrm{d})$ that year. Projects in Mexico to increase pipeline capacity are underway and are expected to import more than $5 \mathrm{Bcf} / \mathrm{d}$ of natural gas by 2020 . With pipeline capacities expansions and few LNG import terminals, it is expected that LNG imports will be displaced by cheaper natural gas from the United States (EIA, [20I5c).

On an assessment made by the Energy Information Administration (EIA), Mexican technically recoverable shale resources are ranked as the 6 th largest in the world (Congressional Research Service, 2015). Gas resources are largely concentrated in the Northeast and South-Southeast regions of Mexico. The Burgos Basin in the Northeast contains approximately 393 Tcf of Mexico's technically recoverable shale gas resources, most of the country's prospective reserves. However, in the first semester of 2014, Pemex announced plans on drilling 10 shale test wells, a small number compared with the more than 27,000 wells drilled in Texas in the same year (EIA, [2015c). Therefore, in order to scale up shale gas production, the Mexican government needs to address issues regarding lack of infrastructure and capacity expansion. In order to promote natural gas production in Mexico and reduce reliance on U.S. imports, on December 20, 2013, the Mexican government promulgated the Energy Reform. The initiative opened up new opportunities for the private sector in the upstream (exploration, development, and production) and downstream (refining and marketing of the resource) sector of the oil and gas industry. On what was called the 'Round Zero' of the reform, Pemex was awarded with $83 \%$ of the country's probable reserves and $21 \%$ of its prospective reserves. Independent bids to develop fields of both unconventional and conventional natural gas resources will probably come through partnerships with Pemex in profit-sharing contracts (Congressional Research Service, ¿U15). Pemex will remain a state-owned company but will be given more budgetary and administrative autonomy. The energy reforms also call for empowering the regulatory agencies of SENER (Secretaria de Energía) and The National Hydrocarbon Commission (CNH), and for creating the Agencia de Seguridad, Energa y Ambiente (ASEA), a new environmental protection agency (EIA, 2015c).

\footnotetext{
${ }^{1}$ See further details at https://www.eia.gov/todayinenergy/detail.cfm?id=16471. Accessed on January 19, 2016.
} 
With the opening of Mexico's energy industry, shale development has been one of the areas gathering interest. Some gas formations in northern Mexico are attractive to U.S. companies due to their proximity to developments in Texas (Congressional Research Service, 2015). As an example, the Burgos Basin in the Northeast is an extension of the Eagle Ford Basin, a development in Texas with good recovery rates. With this context, pipeline imports from the United States into Mexico are most likely to continue growing, particularly in areas that are not connected to other parts of the country (Northwest Mexican region) (ETA, [2014). A detailed description of the Mexican territory is provided in Section 2 .

With the likely changes in the natural gas demand and infrastructure, models with more granularity in terms of regions and pipelines are needed. The main goal of this effort is to develop such a model. This paper presents the North American Natural Gas Model (NANGAM). It is a long-term partial-equilibrium model of the natural gas markets including Canada, the U.S., and Mexico. NANGAM is the first natural gas model that considers a high granularity in terms of geography (regions) and infrastructure (pipelines and supply) in North America, specifically Mexico. Further details of NANGAM are presented in Section [1. We use NANGAM to study the impacts of new energy regulations in Mexico on the North American continent by analyzing the cost and benefits of cross-border flows on natural gas.

Other models in the literature, while also being large-scale numerical applications, do not consider a sufficiently high level of detail of the infrastructure in North America, in particular for Mexico. For instance, one of the first natural gas models with focus in North America is the Gas Trade Model (GTM, Beltramo et al, 1986). The GTM was developed in the late 80's and considered Mexico as a single demand-production node. A large scale linear complementarity model for North America was presented in Gabriel et al. (2005b). Even though the model has a high granularity of the U.S., the Mexican gas market was not taken into account. Also, this model did not consider endogenous capacity expansion decisions. The World Gas Model (WGM) described in Egging et al. (20IU), an extension of the work developed in Gabriel et al. (2005b) and Gabriel et al (2005a), considered six regions in the U.S and treated Mexico as a single region. The authors in Siddiqui and Gabriel (2013) used the WGM to study the impact of a shale producer having market power. Authors expanded the number of regions in the U.S. to 10, but kept Mexico and Canada as single regions. A model similar in scope to the WGM is the Global Gas Model (GGM, Egging, 201.3), but it includes more features and functionality with regard to stochastic scenarios.

The Gas Market Modeling with Energy Substitution (GaMMES) developed in Abada et al. (2013) (a generalized Nash Cournot model) did consider endogenous decisions for capacity expansion and long-term contracts but it was used to study the northwestern European natural gas trade. The FRISBEE model (Aune et al, , 200.). is a recursively dynamic partial-equilibrium model with 13 global regions. However, Mexico is not considered among them. The model developed in Huppmann and Egging (2014) represents Europe by 15 nodes, of which eleven are European union (EU) member states (or aggregates thereof). The rest of the world is aggregated into thirteen nodes by continent or major regions. Models that have a focus on the European market include GASMOD (Holz et al, 20108), GaMMES (Abada et al, 2013, described earlier), and GASTALE (Boots et al., 2003; Lise and Hobbs, 2009). Other models with a European focus that analyze imperfect competition a la Cournot among gas producers include Boots et all (2004), Egging and Gabriel (2006), and Lise and Hobbs (2008). Finally, Gridnet (www.rbac.com) and ICFs Gas Market Model (ICF GMM ${ }^{[ \pm}$) offer high details on U.S. coverage, but are designed to support short- and medium-term decisions. A more detailed summary and comparison of some of the gas market models described here can be found in Gabriel et al] (सणI2).

\footnotetext{
${ }^{2}$ http://www.icfi.com/insights/products-and-tools/gmm
} 
As mentioned above, different models have been used to study the global and the North American gas market (e.g., Gabriel et al, 2005b; Egging et al., 2010; Gabriel et al., 2005a; Siddiqui and Gabriel, 2013; Gabriel et al., 2012)). Richter (2015) critically discusses the potential of U.S. shale gas projections and uses GGM to analyze the impact of alternative outlooks on the global natural gas market. However, all of these models treat Mexico as a single node, or exclude it completely. In contrast, we increase the granularity of the Mexican territory and consider five consumption/production market regions as well as more details regarding gas infrastructure (pipelines) network (see Section $\square$ ). Another important feature that distinguishes NANGAM from other previous natural gas models is that NANGAM incorporates endogenous capacity expansion in both production and pipeline infrastructure while using a logarithmic cost function for gas supply (Golombek et al, 199.9). Also, NANGAM considers up-to-date data and projections (used for calibration) and hence it better represents recent developments due to the shale gas boom, especially in the U.S. The model also includes three seasons (low, high, peak) each with load/production variations, and gas storage operators to account for seasonal demand changes (see details in Section B).

The rest of the paper is organized as follows. Section $\square$ describes the Mexican territory and its natural gas markets. Details of the NANGAM model are presented in Section 3. The description of the data set and different future scenarios are presented in Section 6 . Results of the future scenarios are presented in Section 5 . Concluding remarks are in Section [6.

\section{Description of the Mexican Market and the Energy Re- form}

Mexico's national territory is divided into five market regions: Northwest (Mex1), Northeast (Mex2), Interior-West (Mex3), Interior (Mex4), and South-Southeast (Mex5 SEINER, [2013). Figure $\mathbb{W}$ shows a representation of the Mexican territory. The Northwest and Northeast regions receive all natural gas from the U.S., which is imported both through private pipelines and pipelines owned by Pemex Gas y Petroqumica Básica (PGPB), Pemex' natural gas subsidiary. Some of the imports arrive in areas in the Northwest that do not have other ways to access natural gas (ETA, [2014). Offshore oil platforms operated by Pemex in the South-Southeast account for $75 \%$ of the country's domestic natural gas production (EIA, [2014). Much of the gas imported in the Northeast is used in industrial and power plants, and a large amount is sent to Mexico's interior regions. Consumption growth in natural gas is projected for all five regions. The Mexican energy ministry, SENER, estimates that between 2012 and 2027 about $75 \%$ of consumption growth is predicted to be in the electric sector driven by independently operated power plants ( $\underline{\mathbb{E} I A},[\mathbf{Z I I})$. For instance, the contribution of natural gas in electricity generation increased from $12.1 \%$ in 1996 to $42.6 \%$ in 2006 , representing an average annual growth rate of $17.9 \%$ (Santoyo-Castelazo et al., 20II).

Table 1: Pipelines among regions in Mexico and the U.S.

\begin{tabular}{c}
\hline Pipelines \\
\hline Northeast $\leftrightarrow$ South-Southeast \\
South-Southeast $\leftrightarrow$ Interior \\
Interior $\leftrightarrow$ Interior-West \\
US7 $\leftrightarrow$ Northeast \\
US8 $\leftrightarrow$ Northwest \\
\hline
\end{tabular}

In 2013, Mexico's dry natural production was approximately $1.6 \mathrm{Tcf}$, a small decline from the previous year. More than two-thirds of non-associated gas production 


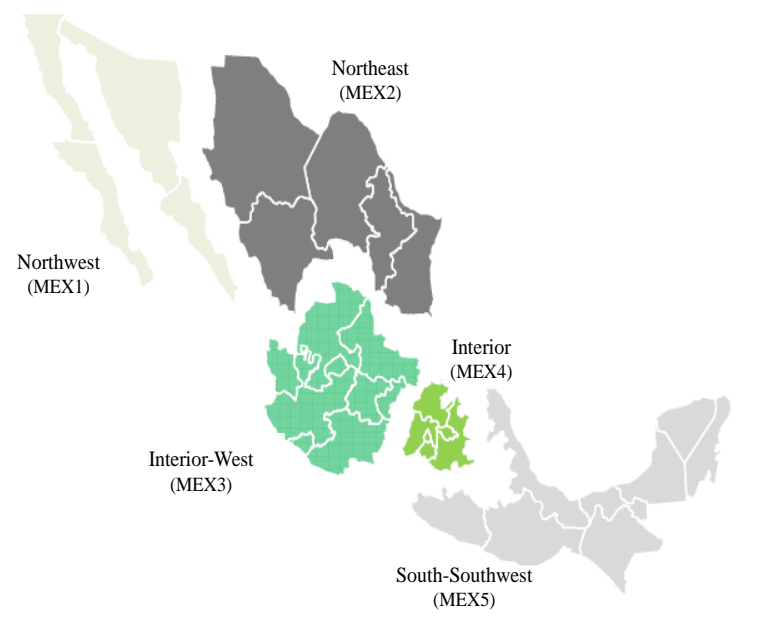

Figure 1: Mexican market regions. Source: Energy Information Administration.

in the country occurred in the Burgos Basin in the Northeast, and most of the remainder from fields in Veracruz in the South-Southeast (EIA, $2015 \mathrm{C})$. Note that the South-Southeast region contains the largest share of proven gas reserves. However, production growth of natural gas in the South-Southeast region is projected to be only $0.4 \%$ per year through 2019 (Congressional Research Service, 2015). Regarding associated gas (as a sub-product of oil production), nearly $75 \%$ of the country's production is from offshore oil platforms operated by Pemex in the South-Southeast region.

With the energy reform, that aims at addressing some of the above mentioned issues, the Peña Nieto government has optimistic projections, including a GDP growth of $1 \%$, lower energy prices, and 500,000 new jobs. Estimates indicate that foreign investments in the country are to increase $\$ 20$ billion each year in 2016 and 2017 (Congressional Research Service, 2015). These investments are expected to take advantage of major unexplored reserves, particularly in the Gulf of Mexico (Year, 2015).

\section{The North American Natural Gas Model}

NANGAM ${ }^{\mathbb{3}}$ is a long-term partial-equilibrium model of the United States, Mexican, and Canadian gas markets. There are currently a total of 17 nodes, of which nine correspond to U.S. census regions, one node to Alaska ${ }^{\text {⿴囗 }}$, two nodes to Canada (East and West), and five to Mexico (Northwest, Northeast, Interior-West, Interior, and South-Southeast). Of the above mentioned nodes, there are 13 nodes with natural gas (shale and non-shale) production capacity (census regions 2-9 for the lower-48 states, one for Alaska, two for Canada, and two for Mexico). The 17 production-demand nodes are currently connected through 69 pipelines. There are also storage facilities at each node in the U.S. and Canada. The model allows for endogenous infrastructure expansion, and is built in five year time-steps starting in 2010 up to 2040, considering three seasons (low, high, and peak) for each time-step.

NANGAM is built based on the MultiMod framework. MultiMod is a spatial and dynamic multi-period representation of the global energy value chain with endogenous

\footnotetext{
${ }^{3}$ NANGAM is written in GAMS and data can be accessed using Microsoft Access. The model will be available to all researchers free of charge under a creative commons license.

${ }^{4}$ Alaska technically belongs to census region 9. However, it was considered that Alaska belongs to a single region in order to model its own increasing supply projections
} 
investment in infrastructure capacity (Huppmann and Egging, 2014). MultiMod represents a market equilibrium between non-cooperative actors in a Nash game, where each player seeks to maximize its individual profits. It allows to include several types of regulatory interventions in the context of climate change mitigation and energy policy (e.g., greenhouse gas emission constraints and taxes, fuel mix mandates, average emission intensity restrictions). MultiMod is formulated as a Mixed Complementarity Problem and can hence include Cournot or conjectural variations, market power for some or all suppliers, as well as use dual variables (i.e., prices) in the players' objective functions.

The current version of NANGAM is calibrated using up-to-date data from the U.S. Energy Information Administration (EIA), Annual Energy Outlook 2015, the Canadian National Energy Board, Mexican Secretary of Energy (Secretara de Energa) SENER, and PEMEX (National Mexican natural gas producer). Details about the NANGAM data set are presented in Section 6 . Note that we aim at matching supply and demand levels at each node for the base year (2010) and projections (until 2040) in the calibration process.

The players in the natural gas supply chain (in NANGAM) include suppliers (upstream), service providers and infrastructure operators (midstream) such as arc operators for pipelines and storage operators, and a final demand (downstream) for an aggregated consumption sector. Each player in NANGAM is profit maximizer. Suppliers produce and sell natural gas. A logarithmic cost function is assumed for suppliers as it better models the costs associated to produce natural gas with low resources. Arc operators allocate possibly congested transmission capacity (based on an implicit auction). This player can be interpreted as a transmission system operator. Storage operators allow suppliers to shift natural gas between yearly seasons (time slices). Final demand for natural gas is modeled via a linear inverse demand curve by sector. For simplicity, NANGAM assumes an aggregated final demand sector. Different sectors (residential, industrial, energy, etc) will be addressed in future research. Also, the mathematical structure of NANGAM also allows for extension to multi-objective programming to determine policies for energy and climate market, as studied in Feijoo and Das (2014), Feijoo and Das (2015), and Siddiqui and Christensen (सण0). Further

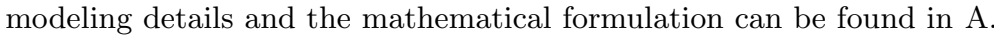

\section{The North American Natural Gas Market: data set and case study}

In this section, the data sources utilized to calibrate NANGAM with are described as well as projections for U.S., Canada, and Mexico. The data set is available upon request (Microsoft Access format). Also, future scenarios are presented.

\subsection{Projections for the U.S.}

Data for production and demand projection in the U.S. were obtained from the Annual Energy Outlook 2015 (AEO2015). Natural gas production in the United States increased by 35\% from 2005 to 2013, with the natural gas share of total U.S. energy consumption rising from $23 \%$ to $28 \%$. The increase in production resulted mainly from the development of shale gas resources in the Lower 48 states and Alaska. According to the AEO2015 reference case, more than $50 \%$ of the total increase in shale natural gas production comes from the Haynesville (southwestern Arkansas, northwest Louisiana, and East Texas) and Marcellus (Pennsylvania, west Virginia, southeast Ohio, and upstate New York) formations. Natural gas production in the U.S. increased from 24.4 Tcf in 2013 
Table 2: Natural gas data sets

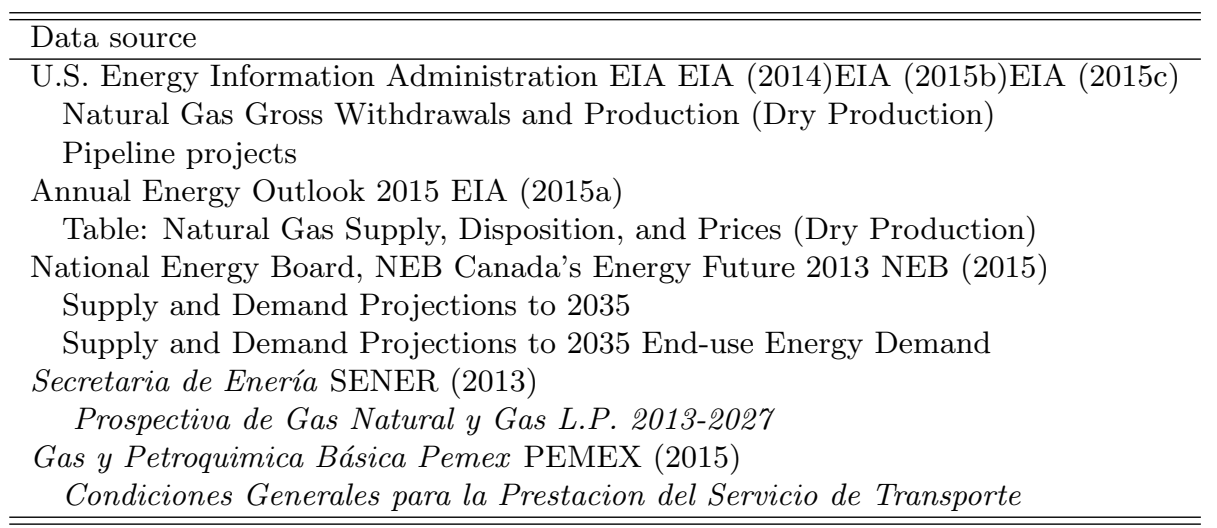

to 35.5 Tcf in 2040, a $45 \%$ increase. Growth in tight gas, federal offshore, and onshore Alaska production also contributes to overall production growth over the projection period. Figure $\square$ shows the projection by census regions in the U.S. (see Figure $\$$ for the division of the census regions considered by NANGAM), where the US7, US8, and US2 are the main producers (representing the Haynesville and Marcellus formations). Also, starting in 2030, there is an increase in Alaska's production (27.4 MMcm/d in 2010 to $89.21 \mathrm{MMcm} / \mathrm{d}$ in 2040). Natural gas demand increases in the U.S. from 1785.35 in 2010 to 2183.78 $\mathrm{MMcm} / \mathrm{d}$ in 2040, with the highest demand being in US7 (512.02 MMcm/d in 2040).

\section{U.S. projection for production till 2040}

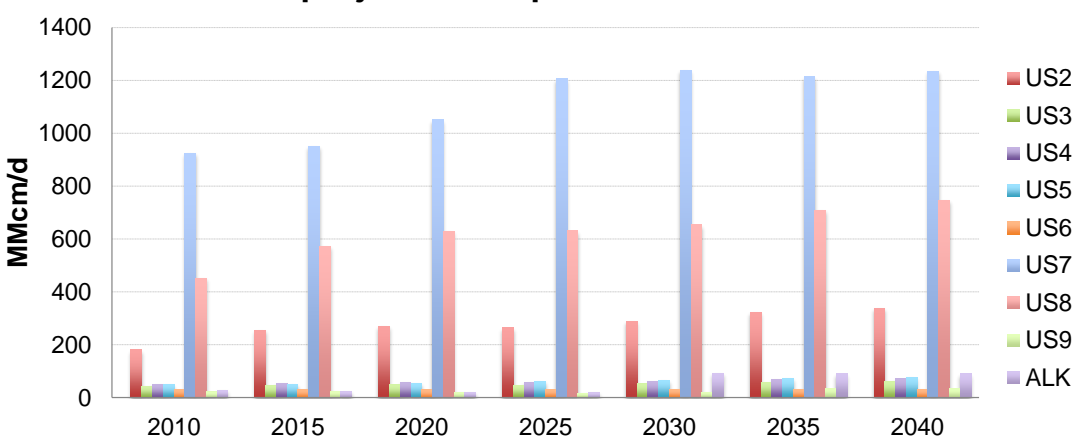

Figure 2: Production projections based on the AEO2015 used for NANGAM calibration

Future dry natural gas production depends primarily on the size and cost of tight and shale gas resources, technology improvements, domestic natural gas demand, and the relative price of oil. According to the AEO2015, United States becomes a net exporter of natural gas in 2017, driven by increased pipeline exports to Mexico, reduced imports from Canada, and LNG exports. 


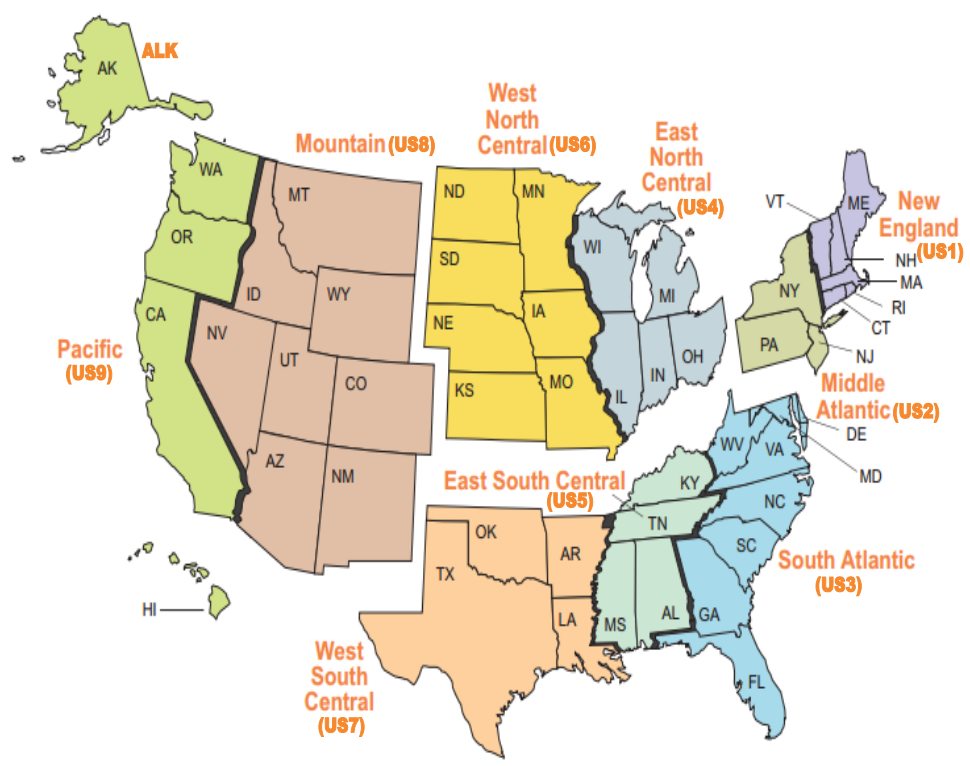

Figure 3: U.S. census regions. Source: Annual Energy Outlook 2015

\subsection{Projections for Mexico}

In order to expand the granularity of the Mexican market and infrastructure, information regarding market regions (with its production and consumption levels), capacities, and pipelines was needed. Information for the market regions were obtained from SENER (Prospectiva de Gas Natural y Gas L.P. 2013-2027 SENER, [2013). Data for pipelines and capacities were obtained from the U.S. Energy Information Administration EIA, and Pemex (PEMEIX, 2015).

U.S. pipeline exports of natural gas flowing south to Mexico have grown substantially since 2010. Exports to Mexico are projected to continue increasing according to the AEO2015, mainly because increasing Mexican production is not expected to keep pace with the country's growing demand for natural gas. Demand is expected to increase $3.6 \%$ yearly (SENER, 2013) through 2027. The demand increase was determined based on the economic activity and fuel prices in Mexico (SENER, 20103). The electric power generation is the main sector and accounts for $75 \%$ of consumption growth between 2012 and 2027 (57\% of the national natural gas demand). The demand increase is shown in Figure 耳, where natural gas production is 2040 is approximately half of the national demand. Consumption growth in natural gas is projected for all five regions. The northeast region is expected to become the largest consumer, overtaking the south-southeast region, accounting for $28.8 \%$ of the total natural gas demand. The south-southeast will represent $25 \%$ of the national demand.

\subsection{Projections for Canada}

Projections for production and demand of natural gas in Canada were obtained from the Canadian National Energy Board (NEB). Canada is the worlds fifth largest producer of natural gas and accounts for around $5 \%$ of global production. Natural gas production in Canada is predominantly from the Western Canadian 


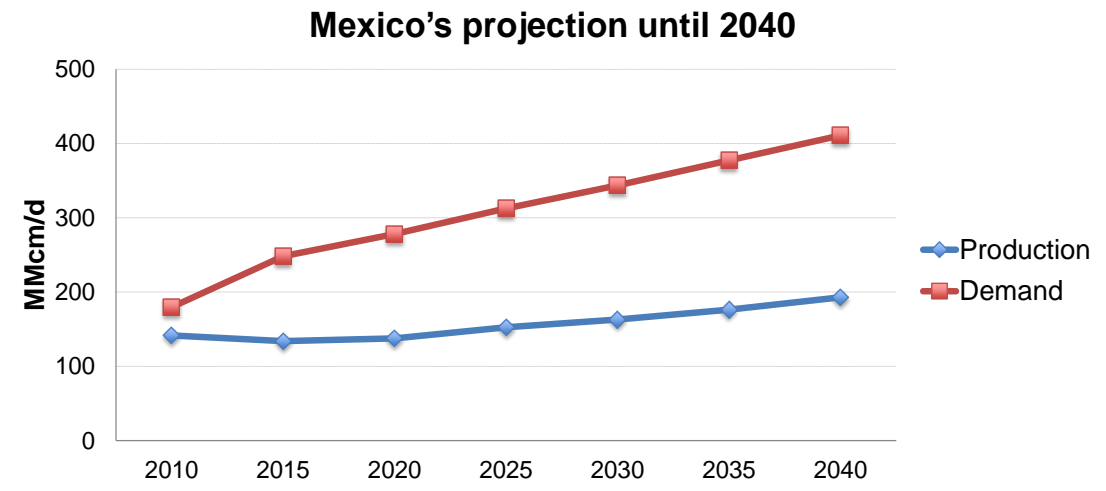

Figure 4: Mexican projections used for NANGAM calibration. Data from SENER, PEMEX and EIA.

Sedimentary Basin (WCSB) in British Columbia, Alberta, and Saskatchewan, although other gas is produced from offshore Nova Scotia and smaller amounts are produced in Ontario, New Brunswick, and Nunavut (태, 2015).

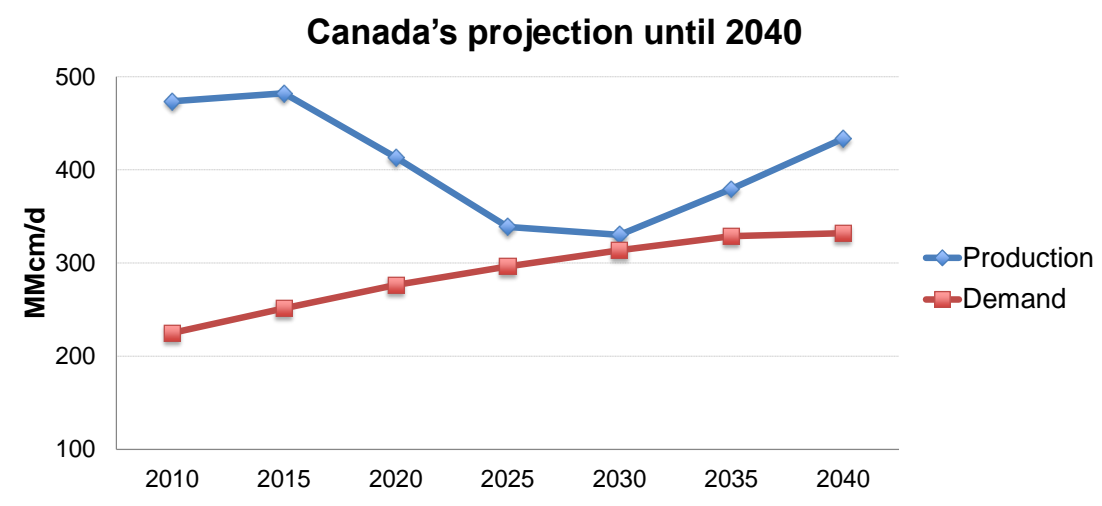

Figure 5: Canadian projections used for NANGAM calibration. Data from the Canadian National Energy Board (NEB).

Figure shows the projection for used in NANGAM for production and demand of natural gas in Canada. Declines in natural gas prices have reduced drilling activity for conventional gas in the WCSB in recent years. However production ramps up continuously until 2035, led by higher levels of tight and shale gas development. Demand for natural gas grows at an annual average rate of $1.7 \%$ over the projection period. This is an increase of over $5.20 \mathrm{Bcf} / \mathrm{d}$ over the projection period, with the largest increases in the industrial and power generation sectors $\mathbb{\mathrm { NEB }}(2015)$.

\subsection{Scenarios in Mexico's production and demand of natural gas}

The Mexican energy reform is likely to change the future scenario of natural gas in North America. Even though projection presented in the AEO2015 or NEB accounted for high demand of natural gas from Mexico, there is huge uncertainty in future infrastructure investments in Mexico. The Mexican Energy reform 
seeks to create incentives to address the increasing demand (from power and industry sectors mainly) and to help Pemex to recover production levels. We present the following scenarios (see Table 3 for a summary) to assess the impact of the success or failure (at different levels) of the Mexican reform;

- Scenario 1) High demand in Mexico without rise in production (failure of the energy reform and increasing demand in Monterrey, MEX2): Increase from the reference demand of natural gas demand in Mexico, mainly at the Northeast (MEX2) region (15\% in 2020 and 5\% yearly based on 2020 thereafter) where Monterrey city is located (one of the main urban cities). Demand increases $10 \%$ starting on 2020 in regions 1 , 3, and 5 and $5 \%$ yearly based on 2020 thereafter. The rise of demand is assumed to be caused by the increasing demand from the energy sector. Production is considered to remain the same as in the given projections.

- Scenario 2) High demand and low resources in Mexico (failure of the energy reform, Burgos and Sabinas are more geologically complex than anticipated): Demand increases as in scenario 1. However, we consider a yearly increase of production cost (for suppliers) of $5 \%$ starting in 2015. This scenario seeks to represent the case in which the energy reform does not attract private investors due to increasing cost generated by the complexity of extraction of natural gas at Burgos and Sabinas basins (northeast and southeast regions).

- Scenario 3) High resources in Mexico (success of the energy reform): Assuming the energy reform will attract private investors, we consider the scenario in which there is a $10 \%$ reduction in investment of production capacity at both Northeast and Southeast regions. Also, we assumed a $5 \%$ reduction in production cost starting in 2020 .

- Scenario 4) High demand and high resources in Mexico (success of the energy reform): We assumed an increase demand for natural gas demand as in scenario 1 as well as high resources as in scenario 3 .

Table 3: Natural gas market scenarios

\begin{tabular}{lcccc}
\hline \hline & Scenario 1 & Scenario 2 & Scenario 3 & Scenario 4 \\
\hline High Demand & Yes & Yes & No & Yes \\
High Resources & No & No & Yes & Yes \\
Low Resources & No & Yes & No & No \\
\hline \hline
\end{tabular}

\section{Results and Analysis of Future Scenarios}

NANGAM is used to simulate and study the four scenarios described in Table 3. Recall that NANGAM is calibrated to match production and demand levels in the U.S., Canada, and Mexico for the years 2010 until 2040 with 5-years time steps.

Private pipelines and pipelines owned by PGPB connecting the U.S. and the Northwest and Northeast regions transport all natural gas imports from the 
U.S (see Figure प). Therefore, we focused our attention first on the supply at the region US7 (Texas mainly), as it is the main producer of natural gas with direct pipelines to the Northwest or MEX2 region. Recall that, according to the AEO2015 reference case, more than $50 \%$ of the total increase in shale gas production comes from the Haynesville formation. Figure $\mathbf{6}$ shows the production levels over the time horizon for all scenarios for US7. Differences of up to $303 \mathrm{MMcm} / \mathrm{d}$ (1364 MMcm/d - $1061 \mathrm{MMcm} / \mathrm{d})$ are observed from the scenarios of High demand and low resources in Mexico compared with the scenario of only high resources in Mexico (demand is the same as the reference case). Clearly, in the case where incentives are not enough for private investor to develop resources Mexico (remember that we modeled this as higher production and investment costs), the increasing demand (mainly in the Northeast region) is accompanied with increasing supply in US7.

\section{Texas (US7) production levels}

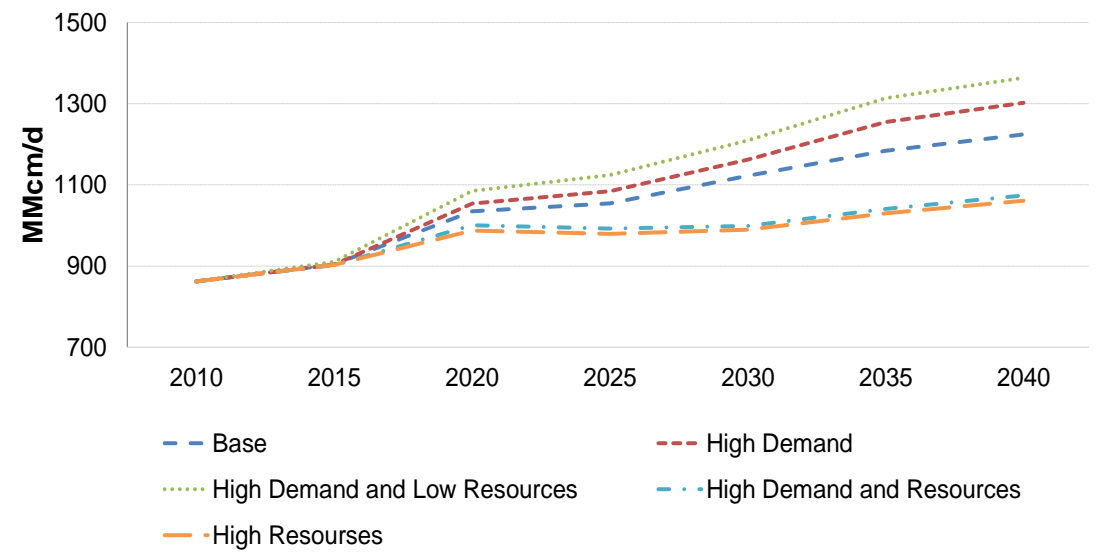

Figure 6: NANGAM results: US7 supply of natural gas for each scenario

Capacity production constraints play a significant role in the determination of the natural gas supply. NANGAM allows for endogenous production capacity investment together with logarithmic cost functions for natural gas ${ }^{\mathbf{w}}$. Figures $\square$ and $\nabla$ show the capacity investment levels in $\mathrm{MMcm} / \mathrm{d}$ (cumulative over the time horizon) for all scenarios for US7 and Mexico, respectively.

Region US7 is significantly impacted by different scenarios in Mexico. Investment capacity is higher than in the reference case for scenarios with low resources in Mexico and high demand. A different pattern is observed in the cases where production and investment costs are lowered in Mexico. We lowered costs to attract private investors, which are expected to develop the infrastructure needed to spur natural gas production in the Northeast, South-Southeast and Gulf of Mexico (EIA, 20150; SEINER, 2013). Remember that a $5 \%$ yearly reduction in production and investment cost was considered.

Investment in capacity production in Mexico is opposite to in US7. Note that Figure $\mathbf{8}$ considers the combined investment of the Northeast and SouthSoutheast regions. Creating incentives that lower production and investment

\footnotetext{
${ }^{5}$ The study presented in Huppmann (201:3b) provides a proof that combining endogenous investment decisions and a logarithmic cost function yields a convex minimization problem.
} 


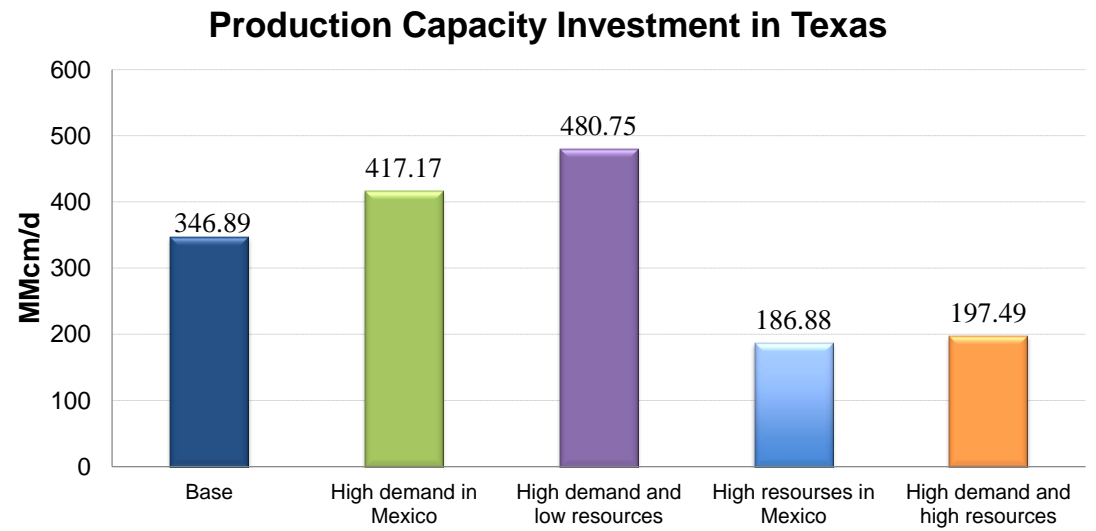

Figure 7: Production capacity investment in U.S. census region 7

costs in Mexico will likely result in the development of the infrastructure and

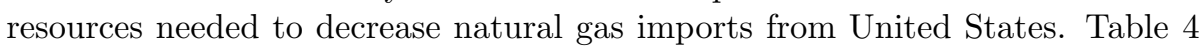
presents these changes in imports from the U.S. and among nodes within Mexico for all scenarios. The changes are calculated as the deviation from the base or reference scenario (relative changes from the base scenario).

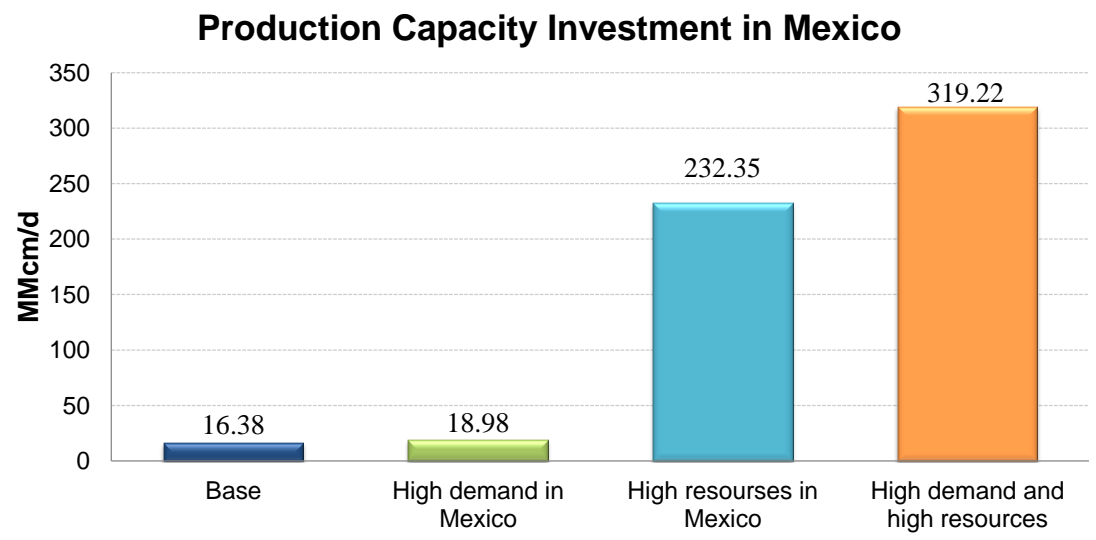

Figure 8: Production capacity investment in Mexico (MEX2 and MEX5 combined)

As expected, higher demand in Mexico increases flows (imports) from US7 into the Northeast (MEX2) region. The increase over the horizon (2010-2040)

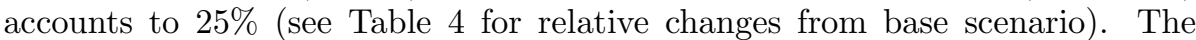
increasing imports are accomplished by increased production $(6 \%$ higher relative to the baseline scenario in 2040) in US7, as it was previously shown in Figure 6. The relative changes in production for all nodes are presented in Tables 5 and 6. When there are low resources in the Northeast and South-Southeast, there is a further increase of imports, reaching a $53 \%$ growth, along with a $11 \%$ higher production in US7 in 2040 (see Table 19). On the other hand, if high resources of natural gas are available in Mexico, flows from US7 decline by $61 \%$ and production is reduced by $13 \%$ in 2040 . 
Table 4: Relative changes from base scenario: Natural gas flows

\begin{tabular}{rcccc}
\hline \hline & $\begin{array}{c}\text { High demand and } \\
\text { low resources }\end{array}$ & $\begin{array}{c}\text { High demand } \\
\text { and resources }\end{array}$ & High demand & High resources \\
\hline MEX2 $\rightarrow$ MEX5 & 1.58 & 0.25 & 1.22 & 0.23 \\
MEX5 $\rightarrow$ MEX4 & 1.11 & 1.13 & 1.11 & 1.01 \\
MEX4 $\rightarrow$ MEX3 & 1.19 & 1.21 & 1.19 & 1.01 \\
US7 $\rightarrow$ MEX2 & 1.53 & 0.39 & 1.25 & 0.33 \\
US8 $\rightarrow$ MEX1 & 1.18 & 1.18 & 1.18 & 1.00 \\
US7 $\rightarrow$ US4 & 0.99 & 1.02 & 0.99 & 1.02 \\
US7 $\rightarrow$ US5 & 0.96 & 1.09 & 0.99 & 1.09 \\
US7 $\rightarrow$ US6 & 0.98 & 1.04 & 0.99 & 1.04 \\
ALK $\rightarrow$ US8 & 1.03 & 0.98 & 1.05 & 0.95 \\
\hline \hline
\end{tabular}

Table 5: Relative changes from base scenario: Natural gas production in scenario of low resources in Mexico

\begin{tabular}{llllllll}
\hline \hline & 2010 & 2015 & 2020 & 2025 & 2030 & 2035 & 2040 \\
\hline ALK & $\mathbf{1 . 0 0}$ & $\mathbf{1 . 0 0}$ & $\mathbf{1 . 0 1}$ & $\mathbf{1 . 0 2}$ & $\mathbf{1 . 0 4}$ & $\mathbf{1 . 0 4}$ & $\mathbf{1 . 0 4}$ \\
CAE & 1.00 & 1.00 & 1.00 & 1.00 & 1.01 & 0.99 & 1.00 \\
CAW & 1.00 & 1.01 & 1.00 & 1.00 & 1.01 & 1.00 & 1.00 \\
US2 & 1.00 & 1.02 & 1.01 & 1.00 & 1.00 & 1.00 & 1.00 \\
US3 & 1.00 & 1.00 & 1.00 & 1.00 & 1.01 & 1.01 & 1.01 \\
US4 & $\mathbf{1 . 0 0}$ & $\mathbf{1 . 0 1}$ & $\mathbf{1 . 0 2}$ & $\mathbf{1 . 0 2}$ & $\mathbf{1 . 0 3}$ & $\mathbf{1 . 0 2}$ & $\mathbf{1 . 0 3}$ \\
US5 & $\mathbf{1 . 0 0}$ & $\mathbf{1 . 0 1}$ & $\mathbf{1 . 0 5}$ & $\mathbf{1 . 0 7}$ & $\mathbf{1 . 0 8}$ & $\mathbf{1 . 0 7}$ & $\mathbf{1 . 0 9}$ \\
US6 & $\mathbf{1 . 0 0}$ & $\mathbf{1 . 0 1}$ & $\mathbf{1 . 0 6}$ & $\mathbf{1 . 0 7}$ & $\mathbf{1 . 0 9}$ & $\mathbf{1 . 0 8}$ & $\mathbf{1 . 1 0}$ \\
US7 & $\mathbf{1 . 0 0}$ & $\mathbf{1 . 0 1}$ & $\mathbf{1 . 0 5}$ & $\mathbf{1 . 0 7}$ & $\mathbf{1 . 0 8}$ & $\mathbf{1 . 1 1}$ & $\mathbf{1 . 1 1}$ \\
US8 & 1.00 & 1.01 & 1.01 & 1.01 & 1.01 & 1.01 & 1.01 \\
US9 & 1.00 & 1.00 & 1.01 & 1.02 & 1.01 & 1.01 & 1.01 \\
MEX2 & $\mathbf{1 . 0 0}$ & $\mathbf{0 . 8 3}$ & $\mathbf{0 . 8 7}$ & $\mathbf{0 . 8 2}$ & $\mathbf{0 . 7 8}$ & $\mathbf{0 . 7 1}$ & $\mathbf{0 . 7 5}$ \\
MEX5 & $\mathbf{1 . 0 0}$ & $\mathbf{0 . 8 2}$ & $\mathbf{0 . 6 5}$ & $\mathbf{0 . 6 1}$ & $\mathbf{0 . 5 4}$ & $\mathbf{0 . 4 5}$ & $\mathbf{0 . 4 9}$ \\
\hline \hline
\end{tabular}

It was also noted that consumption levels in the U.S. are not highly impacted, whereas prices in the U.S. increased/decreased by 1-3\% depending on the scenario. If natural gas production capacity is lower than in the base case, investment in pipelines from Texas and New Mexico will increase flows from the U.S. to satisfy increasing demand. Flows will further increase if there is no infrastructure investment (via incentives on reduced cost in our model). In this case, it was shown that flows from US7 to Monterrey (Mex2) increased by around 53\% (see Table \#, high demand and low resources scenario). However, flows from US7 to connected U.S regions are reduced. Hence, we observed higher natural gas supply in nodes that are connected to US7, as shown in Table 6 . Particularly, nodes US4, US5, and US6 are the most affected. Alaska's production and flows into US8 are also increased by $4 \%$ (increase starts in 2020) and $3 \%$, respectively. Incoming flows from Alaska to US8 help to address increasing demand in the MEX1 region, which receives all the natural gas from the U.S. due to limited pipeline infrastructure within Mexico. Also, Alaska's productions help to address reduced flows from US7 to US4, US5, and US6. Opposite effects 
are observed in the case where investment and production costs are lowered in Mexico (for production regions MEX2 and MEX5), as in scenario 3 (high resources). In this case, natural gas production increases significantly in Mexico by 2040, whereas US4 through US8 and Alaska reduced their supply levels. The region US7 is the most affected, reducing its supply by $13 \%$ in 2035 and 2040 . Even though supply was reduced in US7, its flows into US4, US5, and US6 are increased up to $9 \%$, hence, lowering production in those regions (see Tables

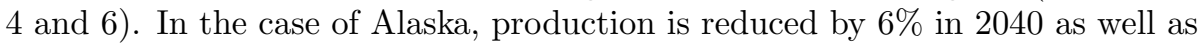
the flows, which were decreased by $5 \%$ in the case of high resources and $2 \%$ in the scenario of high demand and resources in Mexico.

Table 6: Relative changes from base scenario: Natural gas production in scenario of high resources in Mexico

\begin{tabular}{lccccccc}
\hline \hline & 2010 & 2015 & 2020 & 2025 & 2030 & 2035 & 2040 \\
\hline ALK & $\mathbf{1 . 0 0}$ & $\mathbf{1 . 0 0}$ & $\mathbf{1 . 0 0}$ & $\mathbf{0 . 9 8}$ & $\mathbf{0 . 9 5}$ & $\mathbf{0 . 9 4}$ & $\mathbf{0 . 9 4}$ \\
CAE & 1.00 & 1.00 & 1.00 & 1.00 & 1.00 & 0.99 & 0.97 \\
CAW & 1.00 & 1.00 & 1.00 & 0.99 & 0.99 & 0.99 & 0.98 \\
US2 & 1.00 & 0.99 & 0.99 & 0.99 & 0.99 & 0.99 & 0.99 \\
US3 & 1.00 & 1.00 & 1.00 & 1.00 & 1.01 & 1.00 & 1.00 \\
US4 & $\mathbf{1 . 0 0}$ & $\mathbf{1 . 0 0}$ & $\mathbf{0 . 9 9}$ & $\mathbf{0 . 9 7}$ & $\mathbf{0 . 9 7}$ & $\mathbf{0 . 9 7}$ & $\mathbf{0 . 9 7}$ \\
US5 & $\mathbf{1 . 0 0}$ & $\mathbf{1 . 0 0}$ & $\mathbf{0 . 9 8}$ & $\mathbf{0 . 9 1}$ & $\mathbf{0 . 9 1}$ & $\mathbf{0 . 9 2}$ & $\mathbf{0 . 9 0}$ \\
US6 & $\mathbf{1 . 0 0}$ & $\mathbf{1 . 0 0}$ & $\mathbf{0 . 9 7}$ & $\mathbf{0 . 9 0}$ & $\mathbf{0 . 9 0}$ & $\mathbf{0 . 9 1}$ & $\mathbf{0 . 8 9}$ \\
US7 & $\mathbf{1 . 0 0}$ & $\mathbf{1 . 0 0}$ & $\mathbf{0 . 9 5}$ & $\mathbf{0 . 9 3}$ & $\mathbf{0 . 8 8}$ & $\mathbf{0 . 8 7}$ & $\mathbf{0 . 8 7}$ \\
US8 & 1.00 & 0.99 & 0.99 & 0.99 & 0.99 & 0.99 & 0.99 \\
US9 & 1.00 & 1.00 & 1.00 & 0.99 & 1.01 & 1.01 & 1.01 \\
MEX2 & $\mathbf{1 . 0 0}$ & $\mathbf{0 . 9 9}$ & $\mathbf{1 . 1 3}$ & $\mathbf{1 . 6 6}$ & $\mathbf{2 . 3 9}$ & $\mathbf{2 . 4 4}$ & $\mathbf{2 . 4 9}$ \\
MEX5 & $\mathbf{1 . 0 0}$ & $\mathbf{1 . 0 9}$ & $\mathbf{1 . 5 6}$ & $\mathbf{1 . 8 8}$ & $\mathbf{2 . 2 0}$ & $\mathbf{2 . 4 4}$ & $\mathbf{2 . 5 3}$ \\
\hline \hline
\end{tabular}

\section{Conclusions and Outlook}

According to projections of the 2015 Annual Energy Outlook EIA (2015a), the U.S. is expected to become a net exporter of fossil fuels due to strongly increasing shale gas and oil production. Natural gas, in particular, has gained significant importance due to its low emissions rate and competitive prices compared to alternative energy sources. Mexico, through its ongoing energy reform, seeks to spur the development of gas resources by opening the market to private investors and hence reduce the increasing gas imports to northern Mexican regions from the U.S. Assessing the economic and policy implication of these new trends requires models with updated energy projections and higher granularity for Mexico. This paper presents the dynamic partial-equilibrium model NANGAM, which tackles all these issues.

In the current study, NANGAM is calibrated using the most recent data and projections. We assess the impacts of the Mexican energy reform on North America under different scenarios. We found that, in order to spur natural gas supply, Mexico highly depends on economic incentives that reduce barriers to infrastructure investment and keep production costs at competitive levels. As shown using NANGAM, an expansion of the Mexican gas market will reduce 
dependency on U.S. pipelines imports. NANGAM endogenously predicts investment strategies in Mexico that are sufficient to reduce imports to the Northeast region of Mexico. Hence, a corresponding reduction of production levels in the U.S. is also observed, mainly in Texas and Louisiana (census region US7). Reduced exports to Mexico results in higher flows within the U.S., as production volumes from US7 to Mexico are redirected eastwards and to the Midwest (in particular census regions US4, US5, and US6).

In an alternative scenario, we assume that the incentives created by the energy reform are not sufficient to generate the required capacity expansion in Mexico to reduce import dependence. As a consequence, growing natural gas demand in Mexico is satisfied by further increasing supply from US7. As flows from US7 to Mexico grow, a ripple effect of higher supply in Alaska, US4, US5, and US6 is observed. In this scenario, Alaska plays a key role in supplying gas to the Northwest region. The success of the Mexican energy reform will therefore play an important role in the further development of the natural gas sector in North America. It will determine whether the current flow of natural gas from north to south will prevail, or whether Mexico will increase its selfsufficiency with regard to natural gas, reversing the current flow pattern across the continent.

In any case, the Mexican energy reform will only be one step in an ongoing overhaul of the North American energy landscape: the technological revolution facilitating the shale gas boom is the pull factor in the current transformation. On the push side are growing concerns over climate change and emissions from fossil fuel combustion, whether in power generation, heating or transportation. The emission reduction measures recently announced by the U.S. EPA and the creation of a Mexican environmental protection agency indicate the increasing need for policies to manage the transition towards a clean and sustainable energy system.

Analyzing the impacts of such regulatory interventions and the interdependence with competitive markets requires sophisticated models such as NANGAM. We plan to extend the modeling framework to account for stochasticity and conflicting objectives in energy and climate policies via multi-objective optimization (Feijoo and Das, 2014; Siddiqui and Christensen, 2016). A stochastic framework is needed to tackle the ambiguity of available resources, technological developments, and constant environmental regulations that change the direction of the energy sector. Also, we aim at integrating NANGAM with other energy models being developed, including electricity and oil models. Suppliers exerting market power and strategic behaviors from production of various form of gas (e.g., conventional and unconventional), different demand sectors, and environmental regulations (e.g., caps on emissions, taxes, quotas) are also in the outlook of research using NANGAM.

\section{Acknowledgments}

The authors would like to acknowledge Dr. Daniel Shawhan and Dr. Alan Krupnick at Resources for the Future (RFF) for the support and advice given to develop NANGAM. 


\section{A Optimization model for players in NANGAM}

\section{A.1 The supplier}

Each natural gas supplier maximizes its profits from selling gas, considering costs for production, transportation and transformation ${ }^{\mathbf{6}}$. Losses during production, transportation and transformation are considered by the supplier in the nodal mass balance constraint. Suppliers may behave as competitive (i.e., price-taking behavior) or act as a Cournot player; the parameter $\operatorname{cour}^{S}$ is 1 in the latter case, and 0 in the former. Intermediate conjectural variations (CV) values are also possible. See Huppmann (2013a) for a discussion on the (difficulties regarding the) interpretation of using $\mathrm{CV}$ as "exerting market power".

$$
\begin{aligned}
& \max _{\substack{q^{P}, q^{A}, q^{C} \\
q^{O-}, q^{O+}, q^{D}, z^{P}}} \sum_{\substack{y \in Y, h \in H \\
n \in N, e \in E}} d f_{y s}^{S} d u r_{h}\left(\sum_{d \in D}\left[\operatorname{cour}_{y s n d}^{S} \Pi_{y h n d e}^{D}(\cdot)+\left(1-\operatorname{cour}_{y s n d}^{S}\right) p_{y h n d e}^{D}\right] q_{y h s n d e}^{D}\right. \\
&-\operatorname{cost}_{y h s n e}^{P}(\cdot)-\sum_{a \in A_{n e}^{+}} p_{y h a e}^{A} q_{y h s a e}^{A}-\sum_{c \in C} p_{y h n c e}^{C} q_{y h s n c e}^{C} \\
&-\sum_{o \in O_{e}^{E}}\left(p_{y h n o}^{O-} q_{y h s n o}^{O-}+p_{y h n o}^{O+} q_{y h s n o}^{O+}\right) \\
&\left.-\sum_{g \in G} p_{y n g}^{G} e m s_{y s n e g}^{P} q_{y h s n e}^{P}-i n v_{y s n e}^{P} z_{y s n e}^{P}\right)
\end{aligned}
$$

${ }^{6}$ Note that emissions cost are not studied in the current version of NANGAM. However we still provide the complete mathematical formulation for NANGAM, including emissions cost for each player 


$$
\begin{array}{r}
q_{y h s n e}^{P} \leq a v l_{y h s n e}^{P}\left(\operatorname{cap}_{y s n e}^{P}+\sum_{y^{\prime}<y} d e p_{y^{\prime} y s n e}^{P} z_{y^{\prime} \text { sne }}^{P}\right) \quad\left(\alpha_{y h s n e}^{P}\right) \\
\sum_{h \in H_{v o}^{V}} d u r_{h} q_{y h s n o}^{O+}=\sum_{h \in H_{v o}^{V}} d u r_{h}\left(1-l o s s_{o}^{O-}\right) q_{y h s n o}^{O-} \quad\left(\alpha_{y v s n o}^{O}\right) \\
\left(1-\operatorname{loss}_{\text {sne }}^{P}\right) q_{y h s n e}^{P}-\sum_{d \in D} q_{y h s n d e}^{D} \\
+\sum_{c \in C, f \in E_{c}^{C-}} \operatorname{trans}_{\text {yncfe }}^{C} q_{y h s n c f}^{C}-\sum_{c \in C} q_{y h s n c e}^{C} \\
+\sum_{a \in A_{n e}^{+}}\left(1-\operatorname{loss}_{a e}^{A}\right) q_{y h s a e}^{A}-\sum_{a \in A_{n e}^{-}} q_{y h s a e}^{A} \\
+\sum_{o \in O_{e}^{E}}\left(q_{y h s n o}^{O+}-q_{y h s n o}^{O-}\right)=0 \quad\left(\phi_{y h s n e}\right) \\
\sum_{y \in Y, h \in H} d u r_{h} q_{y h s n e}^{P} \leq h o r_{\text {sne }}^{P} \quad\left(\gamma_{\text {sne }}^{P}\right)
\end{array}
$$

The production cost function extends the one proposed by Golombek et al. ([1995), which yields the marginal cost function given below (Equations एaएव). For conciseness, $\widehat{\operatorname{cap}}_{\text {yhsne }}^{P}$ defines the available capacity including prior expansions as defined in Equation एా.

$$
\begin{aligned}
& \operatorname{cost}_{\text {yhsne }}^{P}(\cdot)=\left(\operatorname{lin}_{\text {ysne }}^{P}+\operatorname{gol}_{\text {ysne }}^{P}\right) q_{\text {yhsne }}^{P}+q u d_{\text {ysne }}^{P}\left(q_{\text {yhsne }}^{P}\right)^{2} \\
& +\operatorname{gol}_{\text {ysne }}^{P}\left(\widehat{\operatorname{cap}}_{\text {yhsne }}^{P}-q_{\text {yhsne }}^{P}\right) \ln \left(1-\frac{q_{y h s n e}^{P}}{\widehat{\operatorname{cap}}_{\text {yhsne }}^{P}}\right) \\
& \frac{\partial \operatorname{cost}_{\text {yhsne }}^{P}(\cdot)}{\partial q_{y h s n e}^{P}}=\operatorname{lin}_{y s n e}^{P}+2 q u d_{y s n e}^{P} q_{y h s n e}^{P}-g o l_{y s n e}^{P} \ln \left(1-\frac{q_{y h s n e}^{P}}{\widehat{c a p}_{y h s n e}^{P}}\right) \\
& \frac{\partial \operatorname{cost}_{\text {yhsne }}^{P}(\cdot)}{\partial z_{\hat{y} s n e}^{P}}=\operatorname{gol}_{\text {ysne }}^{P} a v l_{\text {yhsne }}^{P} \operatorname{dep} p_{\hat{y} y s n e}^{P}\left(\ln \left(1-\frac{q_{y h s n e}^{P}}{\widehat{\operatorname{cap}}_{\text {yhsne }}^{P}}\right)+\frac{q_{y h s n e}^{P}}{\widehat{\operatorname{cap}}_{\text {yhsne }}^{P}}\right) \\
& \text { where } \widehat{\operatorname{cap}}_{\text {yhsne }}^{P}=a v l_{\text {yhsne }}^{P}\left(c a p_{y s n e}^{P}+\sum_{y^{\prime}<y} d e p_{y^{\prime} y s n e}^{P} z_{y^{\prime} \text { sne }}^{P}\right)
\end{aligned}
$$

See Huppmann (2013b) for a discussion that this yields a convex problem.

\section{A.2 The arc operator}

By assumption, there is one independent operator for each arc. ${ }^{\square}$ Each arc can carry multiple gas types, with a weight factor to align different units of

\footnotetext{
${ }^{7}$ Given that the infrastructure service providers are price takers, this yields the same model functionality as when there would have been a single arc operator for all the arcs in the system.
} 
measurements if necessary. For simplicity, the emission price is always paid at the starting node of the arc.

$$
\max _{f^{A}, z^{A}} \sum_{y \in Y, h \in H} d f_{y a}^{A} d u r_{h}\left(\left(p_{y h a e}^{A}-t r f_{y a e}^{A}\right) f_{y h a e}^{A}-\sum_{g \in G} p_{y n g}^{G} e m s_{y a e g}^{A} f_{y h a e}^{A}-i n v_{y a}^{A} z_{y a}^{A}\right)
$$

$$
\text { st } \begin{array}{r}
\sum_{e \in E_{a}^{A}} w g t_{\text {ae }}^{A} f_{y h a e}^{A} \leq c a p_{y a}^{A}+\sum_{y^{\prime}<y} d e p_{y^{\prime} y a}^{A} z_{y^{\prime} a}^{A} \quad\left(\tau_{y h a}^{A}\right) \\
z_{y a}^{A} \leq e x p_{y a}^{A} \quad\left(\zeta_{y a}^{A}\right)
\end{array}
$$

\section{Market clearing}

$$
\sum_{s \in S} q_{y h s a e}^{A}=f_{y h a e}^{A} \quad\left(p_{y h a e}^{A}\right)
$$

\section{A.3 The storage operator}

The storage operator allows suppliers to transfer natural gas between different seasons (low, high, peak) within a year. The capacity constraint (i.e., maximum quantity stored) is the summation over all gas injected over a loading cycle. We assume that all costs (losses and emissions) are accounted for during injection. The storage operator only assigns the available capacity. The balancing of gas that is extracted and injected (after losses) is modeled in the supplier's optimization problem.

$$
\begin{array}{r}
\max _{\substack{f^{O-}, f^{O+} \\
z^{O}, z^{O-}, z^{O+}}} \sum_{y \in Y, h \in H} d f_{\text {yno }}^{O} d u r_{h}\left(\left(p_{\text {yhno }}^{O-}-\operatorname{tr} f_{\text {yno }}^{O-}\right) f_{\text {yhno }}^{O-}+p_{\text {yhno }}^{O+} f_{\text {yhno }}^{O+}-\sum_{g \in G} p_{\text {yng }}^{G} \text { ems } s_{\text {yog }}^{O-} f_{\text {yhno }}^{O-}\right. \\
\left.-i n v_{\text {yno }}^{O} z_{\text {yno }}^{O}-i n v_{\text {yno }}^{O-} z_{\text {yno }}^{O-}-i n v_{\text {yno }}^{O+} z_{\text {yno }}^{O+}\right)
\end{array}
$$

$$
\begin{aligned}
& \text { st } \sum_{h \in H_{v o}^{V}} d u r_{h} f_{\text {yhno }}^{O-} \leq c a p_{\text {yno }}^{O}+\sum_{y^{\prime}<y} \operatorname{dep}_{y^{\prime} \text { yno }}^{O} z_{y^{\prime} n o}^{O} \quad\left(\tau_{\text {yvno }}^{O}\right) \\
& f_{y h n o}^{O-} \leq c a p_{y n o}^{O-}+\sum_{y^{\prime}<y} \operatorname{dep}_{y^{\prime} y n o}^{O-} z_{y^{\prime} n o}^{O-} \quad\left(\kappa_{y h n o}^{O-}\right) \\
& f_{\text {yhno }}^{O+} \leq \operatorname{cap}_{\text {yno }}^{O+}+\sum_{y^{\prime}<y} \operatorname{dep}_{y^{\prime} \text { yno }}^{O+} z_{y^{\prime} n o}^{O+} \quad\left(\kappa_{y h n o}^{O+}\right) \\
& z_{\text {yno }}^{O} \leq \exp _{\text {yno }}^{O} \quad\left(\zeta_{y n o}^{O}\right) \\
& z_{\text {yno }}^{O-} \leq \exp _{\text {yno }}^{O-} \quad\left(\zeta_{\text {yno }}^{O-}\right) \\
& z_{\text {yno }}^{O+} \leq \exp _{\text {yno }}^{O+} \quad\left(\zeta_{\text {yno }}^{O+}\right)
\end{aligned}
$$




\section{Market clearing}

$$
\begin{aligned}
& \sum_{s \in S} q_{y h s n o}^{O-}=f_{y h n o}^{O-} \quad\left(p_{y h n o}^{O-}\right) \\
& \sum_{s \in S} q_{y h s n o}^{O+}=f_{y h n o}^{O+} \quad\left(p_{y h n o}^{O+}\right)
\end{aligned}
$$

\section{A.4 Final demand}

The current version of NANGAM considers an unique demand sector. This sector maximizes its utility from the total energy consumption, after accounting for gas and emission costs. We assume the final demand to be a price-taker. For notational convenience, the decision variables of final demand (energy consumed) is denoted by $Q^{D}$ in the utility maximization problem below:

$$
\begin{aligned}
\max _{Q^{D}} \sum_{\substack{y \in Y, h \in H \\
n \in N, e \in E}}\{ & {\left[i n t_{y h n d}^{D}-\frac{1}{2} s l p_{y h n d}^{D}\left(\sum_{f \in E} e f f_{y n d f}^{D} Q_{y h n d f}^{D}\right)\right]\left(e f f_{y n d e}^{D} Q_{y h n d e}^{D}\right) } \\
& -p_{y h n d e}^{D} Q_{y h n d e}^{D} \\
& \left.-e u c c_{y h n d e}^{D} Q_{y h n d e}^{D}-\frac{1}{2} e u c l_{y h n d e}^{D}\left(Q_{y h n d e}^{D}\right)^{2}-\sum_{g \in G} p_{y n g}^{G} e m s_{y d e g}^{D} Q_{y h n d e}^{D}\right\}
\end{aligned}
$$

The linear inverse demand curve is obtained by taking the first-order condition of the quadratic utility maximization problem.

$$
\begin{aligned}
p_{y h n d e}^{D}= & \operatorname{eff} f_{y n d e}^{D}\left[i n t_{y h n d}^{D}-\operatorname{sl} p_{y h n d}^{D}\left(\sum_{s \in S, f \in E} e f f_{y n d f}^{D} q_{y h s n d f}^{D}\right)\right] \\
& -e u c c_{y h n d e}^{D}-e u c l_{y h n d e}^{D}\left(\sum_{s \in S} q_{y h s n d e}^{D}\right)-\sum_{g \in G} p_{y n g}^{G} e m s_{y d e g}^{D}
\end{aligned}
$$




\section{References}

Ibrahim Abada, Steven Gabriel, Vincent Briat, and Olivier Massol. A Generalized NashCournot Model for the Northwestern European Natural Gas Markets with a Fuel Substitution Demand Function: The GaMMES Model. Networks and Spatial Economics, 13(1): $1-42,2013$.

Finn Roar Aune, Knut Einar Rosendahl, and Eirik Lund Sagen. Globalisation of Natural Gas Markets-Effects on Prices and Trade Patterns. The Energy Journal, 30(Special Issue): 39-53, 2009 .

Mark A Beltramo, Alan S Manne, and John P Weyant. A North American Gas Trade Model (GTM). The Energy Journal, 7(3):15-32, 1986.

Mehmet Efe Biresselioglu, Tezer Yelkenci, and Ibrahim Onur Oz. Investigating the Natural Gas Supply Security: A New Perspective. Energy, 80:168-176, 2015.

Maroeska G Boots, Fieke AM Rijkers, and Benjamin F Hobbs. GASTALE: An Oligopolistic Model of Production and Trade in the European Gas Market. Energy Research Centre of the Netherlands (ECN), ECN, 35(1), 2003.

Maroeska G Boots, Fieke AM Rijkers, and Benjamin F Hobbs. Trading in the Downstream European Gas Market: A Successive Oligopoly Approach. The Energy Journal, 25(3): 73-102, 2004.

BP. BP Statistical Review of World Energy 2014, 2015. URL http:// WWW.bp.com/content/dam/bp/pdf/energy-economics/statistical-review-2015/ bp-statistical-review-of-world-energy-201b-full-report.pdt.

Congressional Research Service. Mexicos Oil and Gas Sector: Background, Reform Efforts, and Implications for the United States, 2015. URL https://www.fas.org/sgp/crs/row/ R43313.pdt.

Rudolf G Egging and Steven A Gabriel. Examining Market Power in the European Natural Gas Market. Energy Policy, 34(17):2762-2778, 2006.

Ruud Egging. Benders Decomposition for multi-stage stochastic mixed complementarity problems - Applied to a global natural gas market model. European Journal of Operational Research, 226(2):341-353, 2013

Ruud Egging, Franziska Holz, and Steven A Gabriel. The World Gas Model: A Multi-Period Mixed Complementarity Model for the Global Natural Gas Market. Energy, 35(10):40164029, 2010 .

U.S. Energy Information Agency EIA. Mexicos Energy Ministry Projects Rapid NearTerm Growth of Natural Gas Imports from the U.S, 2014. URL http://www.eia.gov/ todayinenergy/detail.cfm?id=16471.

U.S. Energy Information Agency EIA. Natural Gas Gross Withdrawals and Production (Dry Production), 2015a. URL http://www.eia.gov/beta/aeo/\#/?id=13-AE02015\&cases= ref2015. accessed online on December 5th, 2015.

U.S. Energy Information Agency EIA. Natural Gas Gross Withdrawals and Production (Dry Production), 2015b. URL http://www.eia.gov/dnav/ng/ng_prod_sum_a_EPGO_FPD_mmcf_ a.htm. accessed online on December 5th, 2015.

U.S. Energy Information Agency EIA. Mexico international energy data and analysis, 2015c. URL https://www.eia.gov/beta/international/analysis_includes/countries_ long/Mexico/mexico.pdf.

Felipe Feijoo and Tapas K Das. Design of Pareto optimal CO2 Cap-and-Trade Policies for Deregulated Electricity Networks. Applied Energy, 119:371-383, 2014.

Felipe Feijoo and Tapas K Das. Emissions Control via Carbon Policies and Microgrid Generation: A Bilevel Model and Pareto Analysis. Energy, 90:1545-1555, 2015. 
Steven A Gabriel, Supat Kiet, and Jifang Zhuang. A Mixed ComplementarityBasedEquilibrium Model of Natural Gas Markets. Operations Research, 53(5):799-818, 2005a.

Steven A Gabriel, Jifang Zhuang, and Supat Kiet. A Large-Scale Linear Complementarity Model of the North American Natural Gas Market. Energy economics, 27(4):639-665, $2005 \mathrm{~b}$.

Steven A Gabriel, Knut Einar Rosendahl, Ruud Egging, Hakob G Avetisyan, and Sauleh Siddiqui. Cartelization in Gas Markets: Studying the Potential for a Gas OPEC. Energy Economics, 34(1):137-152, 2012.

Rolf Golombek, Eystein Gjelsvik, and Knut Einar Rosendahl. Effects of Liberalizing the Natural Gas Markets in Western Europe. The Energy Journal, 16(1):85-112, 1995.

Franziska Holz, Christian von Hirschhausen, and Claudia Kemfert. A Strategic Model of European Gas Supply (GASMOD). Energy Economics, 30(3):766-788, 2008.

Hillard G Huntington. Industrial Natura Gas Consumption in the United States: An Empirical Model for Evaluating Future Trends. Energy Economics, 29(4):743-759, 2007.

Hillard G. Huntington. Special Issue on the Energy Modeling Forum (EMF) 31: North American Natural Gas and Energy Markets in Transition, 2015. URL https://emf.stanford. edu/. accessed online on January 12th, 2016.

Daniel Huppmann. Endogenous Shifts in OPEC Market Power - A Stackelberg Oligopoly with Fringe. DIW Discussion Paper 1313, 2013a.

Daniel Huppmann. Endogenous Production Capacity Investment in Natural Gas Market Equilibrium Models. European Journal of Operational Research, 231(2):503-506, 2013b.

Daniel Huppmann and Ruud Egging. Market Power, Fuel Substitution and Infrastructure A Large-Scale Equilibrium Model of Global Energy Markets. Energy, 75:483-500, 2014.

W Lise and BF Hobbs. Future Evolution of the Liberalised European Gas Market. Simulation Results with the Dynamic GASTALE Model. Energy Policy, 36(6):1890-1906, 2008.

Wietze Lise and Benjamin F Hobbs. A Dynamic Simulation of Market Power in the Liberalised European Natural Gas Market. The Energy Journal, 30(Special Issue I):119-135, 2009.

NEB. Canada's Energy Future 2013: Supply and Demand Projections to 2035, 2015. URL https://wWw.neb-one.gc.ca/nrg/ntgrtd/ftr/2013/ppndcs/pxgsprdctn-eng.html. accessed online on December 5th 2015.

PEMEX. Condiciones Generales para la Prestacin del Servicio de Transporte de Gas Natural, 2015. URL http://www.pemex.com/comercializacion/servicios/ductos/Documents/ sngrest4b82012.pdt. accessed online on December 5th 2015.

Philipp M. Richter. From boom to bust? - A critical look at US shale gas projections. Economics of Energy \& Environmental Policy, 4(1):131-151, 2015.

E Santoyo-Castelazo, H Gujba, and A Azapagic. Life Cycle Assessment of Electricity Generation in Mexico. Energy, 36(3):1488-1499, 2011.

SENER. Prospectiva de Gas Natural y Gas L.P. 2013-2027, 2013. URL http://sener.gob. $\mathrm{mx} / \mathrm{res} /$ PE_Y_DT/pub/2013/Prospectiva_Gas_Natural_y_Gas_LP_2013-2027.pdf.

Sauleh Siddiqui and Adam Christensen. Determining Energy and Climate Market Policy using Multiobjective Programs with Equilibrium Constraints. Energy, 94:316-325, 2016.

Sauleh Siddiqui and Steven A Gabriel. An SOS1- Based Approach for Solving MPECs With a Natural Gas Market Application. Networks and Spatial Economics, 13(2):205-227, 2013.

The Oil \& Gas Year. The Oil \& Gas Year Mexico 2015, 2015. 